\title{
Canine Osteosarcoma
}

National Cancer Institute

\section{Source}

National Cancer Institute. Canine Osteosarcoma. NCI Thesaurus. Code C120045.

An osteosarcoma of mesenchymal origin in a dog. It is the most common bone cancer in dogs, most often developing in the limbs of large or giant breed dogs. The morphologic and biologic behavior of canine osteosarcomas is similar to that of human osteosarcomas. 